Важнейшими условиями формирования взаимосвязи урочной и внеклассной работы по ОБЖ являются: системный подход, учет познавательных способностей и интересов детей, дифференцированный подход к каждому учащемуся, установление межпредметных связей, создание условий для конструктивного диалога между учителем и его учениками [1].

Таким образом, модель выступает деятельностным средством формирования экологического стиля мышления [3], востребованного на занятиях по ОБЖ. Важно, чтобы внеклассные мероприятия по ОБЖ стали традиционной составляющей работы школы по данному курсу и стали логическим продолжением урочной деятельности.

$$
* * *
$$

1. Головенков, С. Г. Взаимосвязь урочной и внеклассной работы со школьниками по основам безопасности жизнедеятельности [Текст] / С. Г. Головенков // Молодой ученый. — 2015. — №6.4. — С. 80-84.

2. Даутмерзаева, Л.М. Формирование экологического мышления в процессе изучения естественнонаучных дисциплин в средней общеобраовательнои школе [Текст] / Л. М. Даутмерзаева. : автореф. дис. ... канд. пед. наук. Саратов, 2003. С. 21-22.

3. Дзятковская, Е.Н. Методические рекомендации по реализации экологического образования в федеральных государственных стандартах второго поколения [Текст] / Е.Н. Дзятковская, А.Н. Захлебный, А.Ю. Либеров // Образование и экология, М. 2011., №11.

\title{
Подойницына А.А. \\ Особенности преподавания китайского языка как второго иностранного в общеобразовательных организациях Амурской области
}

ГАУ ДПО «Амурский областной институт развития образования»

(Россия, Благовещенск)

doi: $10.18411 / s r-10-12-2017-46$

idsp: 000001:sr-10-12-2017-46

\section{Аннотация}

Статья посвящена проблеме обучения китайскому языку. Амурская область - это область которая находится на границе с Китаем, что обуславливает необходимость изучения китайского языка.В настоящее время, введение второго иностранного языка в общеобразовательных организациях не является обязательным и проводится на уровне факультатива. Таким образом, необходимо разработать комплекс или систему упражнений, способствующих формированию навыков говорения на китайском языке в условиях профильного обучения китайскому языку, как второму иностранному.

Ключевые слова: профильный этап обучения, китайский язык, методика обучения иностранным языкам, комплекс упражнений.

\section{Abstract}

The article is devoted to the problem of teaching Chinese. The Amur region is the region that is located on the border with China. It leads to the necessity of studying Chinese. Nowadays it is not obligatory and it is taught only during different electives. That is why we made a complex of exercises, helping to form speaking skills on Chinese.

Key words:high school, the Chinese language, methods of teaching foreign languages, complex of exercises.

С 1 сентября 2015 г. во всех общеобразовательных организациях Российской Федерации в штатном режиме введён федеральный государственный образовательный стандарт основного общего образования (далее - Стандарт). Стандарт утверждён приказом Министерства образования и науки Российской Федерации от 17 декабря 2010 г., с изменениями, утверждёнными приказами Минобрнауки России от 29 декабря 2014 г. № 1644 и от 31 декабря 2015 года № 1577, и представляет собой совокупность 
требований, обязательных при реализации основной образовательной программы основного общего образования.

В «Методических рекомендациях по вопросам введения федерального государственного образовательного стандарта основного общего образования», подготовленных департаментом государственной политики в сфере общего образования Министерства образования и науки Российской Федерации и оформленных письмом от 7 августа 2015 года № 08-1228, даются разъяснения по вопросу изучения второго иностранного языка.

«8. Является ли обязательным изучение второго иностранного языка?

Стандарт позволяет общеобразовательным организациям в рамках реализации образовательной программы основного общего образования (предметной области«Филология») вводить изучение второго иностранного языка как обязательного.

При составлении своей основной образовательной программы школой может быть использован вариант учебного плана, предусматривающий изучение второго иностранного языка в качестве обязательного, при наличии соответствующего запроса родителей (законных представителей) обучающихся и необходимых условий в школе».

Инструментом реализации ФГОС основного общего образования в образовательных организациях является Примерная основная образовательная программа основного общего образования (одобрена решением федерального учебно-методического объединения по общему образованию (протокол от 8 апреля 2015 г. № 1/15).

В Примерной основной образовательной программе ООО для основного общего образования представлены пять вариантов примерного недельного учебного плана:

- Варианты 1, 2, 3 - для общеобразовательных организаций, в которых обучение ведётся на русском языке с учетом минимального и максимального числа часов (1 и 2 варианты), а также с учетом изучения второго иностранного языка (3 вариант);

- Вариант 4 - для общеобразовательных организаций, в которых обучение ведётся на русском языке, но наряду с ним изучается один из языков народов Российской Федерации;

- Вариант 5 - для общеобразовательных организаций, в которых обучение ведётся на родном (нерусском) языке из числа языков народов Российской Федерации.

Из общеобразовательных организаций Амурской области этот вариант учебного плана №3 реализует МОАУ «Классическая гимназия № 2»г. Тынды, где преподаётся французский язык в качестве второго иностранного, МАОУ «Школа № 14 города Благовещенска», МАОУ «Школа № 26 города Благовещенска» (введён китайский язык со 2 по 11 классы).

В остальных случаях (на ступени начального и среднего общего образования) примерные учебные планы в обязательной части не предусматривают изучение второго иностранного языка. Его введение в учебный план возможно по согласованию со всеми участниками образовательных отношений за счёт части учебного плана, формируемого участниками образовательных отношений.

Целостностьинязычногообразованиядолжнанайтиотражение во всех составляющих образовательной системы (в целях, содержании, в средствах и технологиях). Профильное обучение - это система специализированной подготовки в старших классах общеобразовательной школы, ориентированной на индивидуализацию и специализацию обучающихся.

Основные возрастные особенности учащихся старших классов начинают складываться уже в 8-м классе. Психологи отмечают, что в каждом возрастном периоде наблюдается сосуществование различных ступеней, еще остаются следы предшествующего этапа развития, но уже возникают новые явления, которые могут стать типическими и получить развитие в последующие этапы развития. 
На данном этапе приемы и методы обучения чтению, которые были использованы на среднем и младших этапах оказываются малоэффективными, так как учащиеся старшего возраста неохотно выполняют механические задания, цель которых им неясна. Большую роль в обучении начинает играть самостоятельная работа. Для того чтобы использовать иностранный язык, как средство коммуникации, у учеников данного возраста должны быть сформированы рефлексия своих собственных способностей, а так же рефлексия учебной деятельности во всех ее составляющих компонентах. На старшем этапе учащиеся должны полностью овладеть структурой учебной деятельности и всеми необходимыми учебными умениями и навыками.

Для максимально продуктивного освоения нового материала учащимися учителю необходимо ориентироваться на физиологические, возрастные и психологические особенности обучающихся. Обучение не должно носить «насильственный» характер, а быть добровольным, поэтому учителю необходимо сделать процесс обучения более интересным. Следует подбирать материал и задания к ним, которые на данный момент являются актуальными. При профильном обучении важную роль имеет социокультурный материал, который знакомит с историческим и социокультурным фоном, а также с реалиями языка изучаемой страны.

Иноязычная коммуникативная компетенция в сфере профильного обучения не может сводиться только к обучению делового общения. Преподаватель должен отбирать те виды и типы текстов, которые помогут учащимся реализовать коммуникативные возможности говорения. В настоящее время одной из главных задач обучения китайскому языку на старшем этапе является формирование коммуникативной компетенции обучающихся.

Таким образом, нами был создан комплекс упражнений для школьников по формированию навыков говорения на китайском языке.

Урок по теме 《假劣的物品》

\section{练习一。请读一下生词。}

b ù fěi d e táobăodiànzhŭ

不菲的淘宝 店 主- богатый владелец магазина ТаоБао

píngtái

平 台- площадка

xiāoshòu

销 售 - продавать

jiǎlièshāngp̌̌n

假劣 商 品- подделка

jiānguănzhòngdiăn

监管 重 点- акцент на таможенный досмотр

fángfàncuòshī

防范措施- меры по предосторожности

zhěngzhìd e juéxīn

整治的决心- политическое решение

wánzhèngwèichú

顽症未除- не исчезнувшая «болезнь»

y ěmánshēngzhăng

野蛮生长-рост варварства

j íxū

亟须- регулировать

miànmó

面 膜- маска

qiànr ù

嵌入- заделывать щели, вставлять

guătóushì

寡头式- модель олигархии 
qúnxióngjuézhú

群 雄角逐- конкурирующие военачальники一轮圆 月- следующая полная луна shănshuò

闪 陈 - искриться, жонглировать словами, играть

bèijǐngxià

背景下- на фоне

zhīy ì xíngnán

知易行难- легче сказать, чем сделать

yōuguān

敒 关 - сторона

pínghéng

平 衡-равновесие, баланс

练习二。请看这张图示，还考虑一下课文的题目.

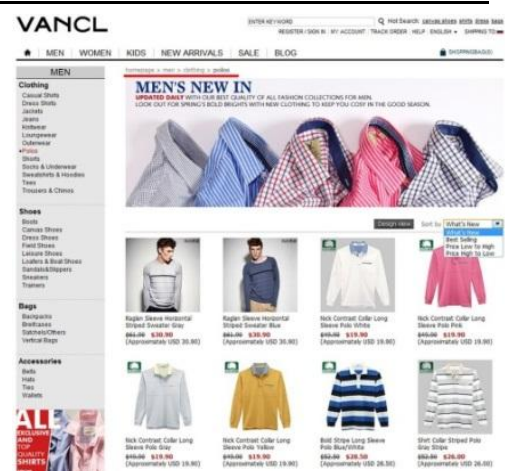

Рис.1. Каталог одежды

练习三。请读一下课文。

pīxīn

足不出户，即可购物，网购确实给生活带来很多便利，由此出现一批新

bùfěidetáobǎodiànzhǔ

的行业，比如每月收入不菲的淘宝 店 主

píngtái

; 也造福了某些区域的经济发展，像农村物美价廉的特产，通过电商平 台

xiāoshòu

可以更好地 销 售 出去。

打击网上销售假少少

，不只是电商巨头需要整肃自身，其中还明确提及，针对利用微信、微博等社交网络 平台制售侵权假冒商品等现象，也要研究相关临管和倘gfàncuòshī

国办此次出台意见措施，并制定治理时间表，反映了互联网领域的侵权假冒行为

的严重性以及 整治的决心。

其实，不只是大型电商平台售假顽症 未米除，这两年步入移动互联网时代之后， y ěmánshēngzhăng 野蛮生 长的微商也亟须规范治理，比如，无孔不入的 面膜

代购中，就藏着不少有毒有害面膜。

今天，当线上与线下越来越难区分，互联网对生活的 quànr ù 越来越深，电商的概念也在不断扩大。从塞头式 
的电商平台，到“网红经济”的兴起，再至内容创业者群 雄角逐 ，在中国电商的夜空版图上，而轮俋圆月旁边，已是群星 闪炼。

每个人都可能是假货的受害者，每个人也都有可能是假货的出售者。在这样的背 㸃景市，如何打假，应该说是一个更加复杂的问题。

电商打假, 知易行难, 说到底还是利益敒关

。目前的监管关键，也还是电商平台。尽管对品牌、消费者与店主而言，电商平台与 他们的利益关系错综复杂, 从在商言商的角度看, 平台很难简单地只替某一方说话, 更多的时候还是在选择利益华䚘点。

可是, 终档

还是应该有超脱的勇气与胆识。长久来看，假问题必定会成为平台发展的拉 1 ù h ù 还是应该有超脱的勇气与胆识。长久来看，假货问题必定会成为平台发展的拦路虎 ，建立健全大数据、完善个人征信体系，政府与企业合力、平台与店主齐心，方有治 本之望。

练习四。完成句子。

1. 足不出户, 即可购物, 网购确实给生活带来很多。。。。

2. 通过电商平台台可以更好地。。。。

3. 打击网上销售假劣商品是《意见》所突出的监管管董点 , 不只是电商巨头。。。

4. 国办此次出台意见措施，并制定治理时间表，反映了互联网领域的侵权假冒 行为的严重性以及。。。。

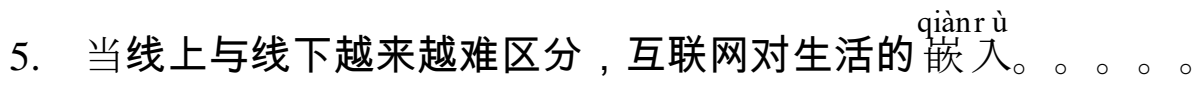

6. 每个人都可能是假货的受害者, 每个人也都有可能是假货的出售者。在这样 bèijīngxià 的背景下, 。。。

7. 电商打假, 知易行推, 说到底还是。。。。。

8. 长久来看, 假货问题必定会成为平台发展的拦路虎 ，建立健全大数据、完善个人征信体系。。。。。

练习五。回答问题。

1. 什么也要研究相关监管和防方范措施?

2. 国办此次出台意见措施包括什么?

3. 野蛮生 长的微商也面须规范治理, 比如说什么?

4. 每个人都可能是什么? 
5. 为什么电商打假知易行行难?

练习六。下列课文部分的顺序被打乱了，请你排出正确(在括号里填上正确的序号 ․ Расположите части текста в правильном порядке

1. 打击网上销售假劣 商器是《意见》所突出的监管重重 点

, 不只是电商巨头需要整肃自身, 其中还明确提及, 针对利用微信、微博等社交网络 平台制售侵权假冒商品等现象，也要研究相关临管和防方范措施

2. 足不出户，即可购物，网购确实给生活带来很多便利，由此出现一批新 的行业，比如每月收入不菲的淘宝店主

; 也造福了某些区域的经济发展，像农村物美价廉的特产，通过电商华台台可以更好地 xiāoshòu 销 售出去。

3. 其实, 不只是大型电商平台售假顽, 症 未来除

，这两年步入移动互联网时代之后，野蛮生 长的微商也篎须

规范治理，比如，无孔不入的 亩面膜代购中，就藏着不少有毒有害面膜。

4. 国办此次出台意见措施，并制定治理时间表，反映了互联网领域的侵权假冒 行为的严重性以及 整治台的决心

5. 电商打假, 知易行难, 说到底还是利益做关

目前的监管关键，也还是电商平台。尽管对品牌、消费者与店主而言，电商平台与 他们的利益关系错综复杂, 从在商言商的角度看, 平台很难简单地只替某一方说话, 更多的时候还是在选择利益平䚘点。

6. 每个人都可能是假货的受害者, 每个人也都有可能是假货的出售者。在这样

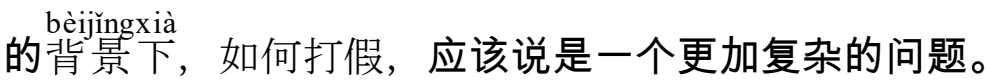

7. 今天, 当线上与线下越来越难区分, 互联网对生活的篏入

越来越深，电商的概念也在不断扩大。从塞头式

的电商平台, 到“网红经济”的兴起, 再至内容创业者群xióngjuézhú

的电商平台, 到“网红经济”的兴起, 再至内容创业者群雄角逐

，在中国电商的夜空版图上，一轮圆月号旁边，已是群星闪炼。

8. 可是, 终归

还是应该有超脱的勇气与胆识。长久来看, 假货问题必定会成为平台发展的拦路虎 ，建立健全大数据、完善个人征信体系，政府与企业合力、平台与店主齐心，方有治 本之望。

练习七。你觉得最好的标题是什么? 为什么?

・假劣商品； 
•销售者的利益;

guătóushì

•寡头式。

练习八。按照课文填表。怎么能监管假劣商品？

Таблица 1.

Образеи упражнения

\begin{tabular}{|c|c|}
\hline 按照课文 & 自己的意见 \\
\hline & \\
\hline & \\
\hline
\end{tabular}

练习九。说出课文的要义(основную мысль текста)。
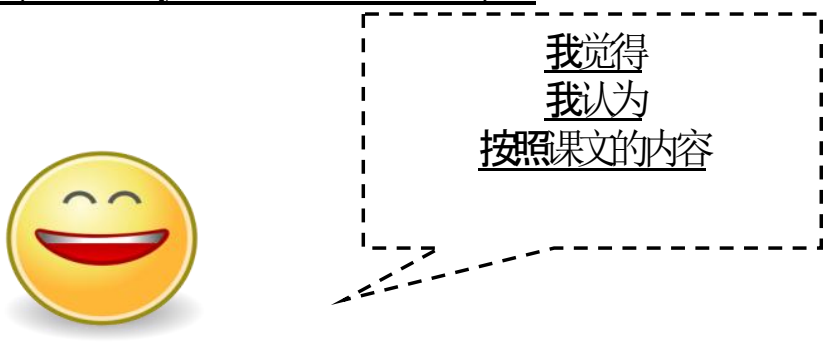

$* * *$

1. Трубина Г.Ф., Психологические особенности старшеклассников и роль мотивации в обучении их иностранному языку / Г.Ф. Трубина //Филологические науки. Вопросы теории и практики. И: Тамбов: «Грамота». - 2013. - №1. - С.180-182.

2. Королева Н.М., Психологические особенности обучения чтению на иностранном языке / Н.М. Королева // Актуальные проблемы современного иноязычного образования. - 2014. - №1. - С. 1-6.

\author{
Самойлова В.М. ${ }^{1}$, Притыченко Л.В. ${ }^{2}$ \\ Применение здоровьесберегающих технологий на занятиях \\ по формированию пространственных представлений у дошкольников \\ подготовительных групп с ОВ3 \\ ${ }^{1}$ МГППУ \\ ${ }^{2}$ ДО № 3 школь № 1321 («Ковчег»)
}

doi: $10.18411 / s r-10-12-2017-47$

idsp: 000001:sr-10-12-2017-47

\title{
Аннотация
}

В статье излагается опыт работы по применению здоровьесберегающих технологий на практических занятиях педагога-психолога по формированию и развитию пространственных представлений у старших дошкольников с ЗПР и ОНР. Авторы статьи определяют цели и задачи каждого этапа работы по формированию пространственных представлений, описывают используемые методы и приемы, формы индивидуальной и коллективной работы.

Ключевые слова: здоровье, психическое здоровье детей, здоровьесберегающая технология, цели здоровье сбережения в ДОУ, пространственное восприятие, коррекция пространственных представлений.

Сегодня в дошкольных учреждениях уделяется большое внимание здоровьесберегающим технологиям, которые направлены на решение самой главной задачи дошкольного образования - сохранить, поддержать и обогатить здоровье детей. Кроме того, серьезной задачей является и обеспечение развития максимально высокого 